\title{
Development and validation of UPLC method for quantitative estimation of related impurities in tizanidine hydrochloride tablets
}

\author{
Sanjay Shesha Shetgar ${ }^{*}$, Ramadevi Dharmasoth², Basavaiah Keloth ${ }^{3}$, Bandlamudi Mallikarjuna Rao ${ }^{4}$ \\ ${ }^{1}$ Department of Inorganic and Analytical Chemistry, Andhra University, Visakhapatnam, India. \\ ${ }^{2} \mathrm{AU}$ College of Pharmaceutical Science, Andhra University, Visakhapatnam, India. \\ ${ }^{3}$ Professor, Department of Inorganic and Analytical Chemistry, Andhra University, Visakhapatnam, India. \\ ${ }^{4}$ Vice President Head, ASAT Corporate Quality Control, Dr. Reddys Laboratories, Bachupally, Hyderabad, India.
}

\section{ARTICLE INFO \\ Received on: 21/04/2021 \\ Accepted on: 18/06/2021 \\ Available online: 05/08/2021}

\section{Key words:}

Quantitative, impurity, LOD,

LOQ, Tizanidine, UPLC.

\begin{abstract}
Tizanidine hydrochloride is known to have several related impurities depending on the manufacturing process. There is no published ultra-performance liquid chromatography (UPLC) method which can simultaneously quantify these impurities. The current work is to design, develop, and validate an UPLC method for simultaneous estimation of all known impurities. Forced degradation studies performed on tablet formulation did not show any purity flags. To achieve sensitive and optimal separation of all the six impurities from the main moiety of Tizanidine, gradient UPLC system with ethylene bridged hybrid C 8 column, $230 \mathrm{~nm}$ UV detection provided an optimum separation. The developed method was quick, with all six impurities eluting within 11 minutes. Low level of impurities could be quantified with limit of detection in the range $0.008 \%-0.028 \%$ and limit of quantitation in the range $0.037 \%-0.057 \%$. Recoveries of all spiked impurities in Tizanidine hydrochloride were well within the range of $85 \%-115 \%$. Thus, the developed UPLC method is sensitive, fast, and provides precise and accurate quantitation of all known impurities in Tizanidine hydrochloride tablets. The developed method is very useful for quantitative estimation of impurities in Tizanidine hydrochloride tablets in routine quality control as well as stability monitoring programs. The method can easily be extended to quantitative cleaning residue determination in pharmaceutical industry.
\end{abstract}

\section{INTRODUCTION}

Tizanidine hydrochloride (Figure 1) is 5-chloro-N(4,5-dihydro-1H-imidazol-2-yl)-2,1,3-benzothiadiazol-4-amine hydrochloride and a central alpha- 2 adrenoceptor agonist. It is used for the treatment of patients who show spasticity due to cerebral or spinal injury (dose could be from as low as 2-36 mg/day) (Coward, 1994; Smith et al., 1994; Wagstaff and Bryson, 1997)

There is no data available on ultra-performance liquid chromatography (UPLC) methods for quantitation of related impurities in Tizanidine tablets. However, Tizanidine tablets monograph is listed in United States Pharmacopoeia USP43-NF38 which describes organic impurities by high performance liquid

\section{"Corresponding Author}

Sanjay Shesha Shetgar, Department of Inorganic and Analytical Chemistry, Andhra University, Visakhapatnam, India.

E-mail: sanjayshetgar@yahoo.com

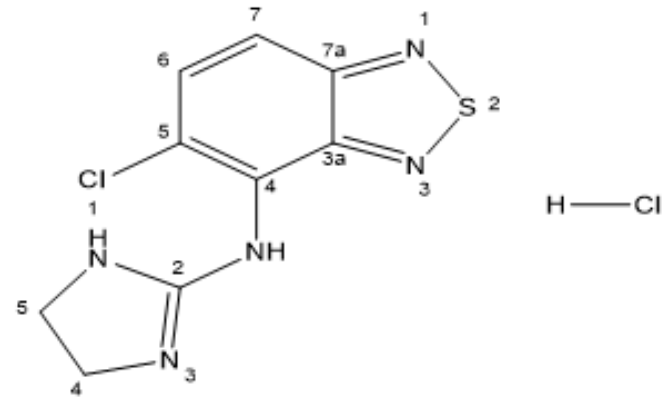

Figure 1. Structure of Tizanidine hydrochloride.

chromatography (HPLC) method for the quantitative estimation of only three known related compounds namely Tizanidine related compound A, Tizanidine related compound B and Tizanidine related compound $\mathrm{C}$. The literature review indicates additional related impurities identified in Tizanidine (Reddy et al., 2008). 
Literature reveals, several analytical methodologies used for the estimation of Tizanidine, either as a single entity or as combined entity with another drug. These methods include spectrophotometric and HPLC methods (Brandalise et al., 2017; Devarajan and Sivasubramanian, 2006; Mantri et al., 2005; Ramaa et al., 2006; Reddy et al., 2008; Samel and Raman, 2009; Subramanian et al., 2004; Vijayakumar et al., 2010). Recent findings have revealed that even significantly low levels of impurities affect the safety as well as the efficacy of a drug product.

Current research work describes quantitation of all known related impurities of Tizanidine hydrochloride Tablets as given in Table 1. Chemical structure of these impurities is given in Figure 2. The operating principle of HPLC and UPLC are the same. Conventional HPLC's use column particle size of about 5 $\mu \mathrm{m}$, while the UPLC's use sub $2-\mu \mathrm{m}$ particle size. Thus, HPLC systems can handle pressures up to $6000 \mathrm{psi}$, whereas UPLC systems can handle pressures up to 15,000 psi. According to Van Deemter equation, the efficiency of a chromatographic process increases with the decrease in column particle size. Smaller the particle size the height equivalent to theoretical plates reduces significantly. In both HPLC an UPLC, the precision and accuracy levels are comparable. However, UPLC offers major advantage with improved sensitivity, faster run time, and reduced solvent consumption. These efficiency advantages make UPLC a soughtafter technique in quality control laboratories. The aim of this study is to develop a quantitative UPLC method which is sensitive, precise, accurate, stability indicating, and quick. This method would also meet the regulatory requirements of ICH (International Council of Harmonisation) and USP (United States Pharmacopeia) validation guidelines for quantitative estimation of related impurities in Tizanidine hydrochloride tablets. Testing labs can use this method for regular testing as well as for stability testing.

\section{MATERIALS AND METHODS}

\section{Materials}

Tizanidine hydrochloride (Purity 99.6\%), Tizanidine hydrochloride tablets $2 / 4 \mathrm{mg}$, and related impurities of Tizanidine hydrochloride were obtained from Dr Reddy's Laboratories, Hyderabad, India as gift samples. Acetonitrile used for mobile phase was of HPLC grade and procured from Merck. Sodium perchlorate and orthophosphoric acid are AR grade chemicals procured from

Table 1. List of related impurities of Tizanidine hydrochloride.

\begin{tabular}{|c|c|c|}
\hline S.No. & Impurity name & Impurity code \\
\hline 1 & N-(4,5-dihydro-1H-imidazol-2-yl)-2,1,3-benzothiazole-4-aminehydrochloride.[Deschloro impurity of Tizanidine hydrochloride] & Impurity A \\
\hline 2 & N-(5-chloro-2,1,3-benzothiadiazol-4-yl)thiourea & Impurity B \\
\hline 3 & Dimer of Tizanidine hydrochloride & Impurity $\mathrm{C}$ \\
\hline 4 & S-methyl-N-(5-chloro-2,1,3-benzothiadiazol-4-yl)-isothiouronium iodide & Impurity D \\
\hline 5 & 4-Amino-5-chloro-2,1,3 benzothiodiazole & Impurity E \\
\hline 6 & $\begin{array}{l}\text { 1-[-n[(5-chloro-2,1,3-benzothiadiazol-4yl)- } \mathrm{N}-(4,5 \text {-dihydro-1H-imidazol-2-yl)amino }]]-1-[-\mathrm{N}-[(5 \text {-chloro-2,1,3-benzothiadiazol-4-yl)- } \\
\text { amino]-methane imine. (Methane imine derivative impurity of tizanidine) }\end{array}$ & Impurity $\mathrm{F}$ \\
\hline
\end{tabular}<smiles>ClN1CCN=C1Nc1cccc2nsnc12</smiles>

(a)<smiles>CSC(N)Nc1c(Cl)ccc2nsnc12</smiles>

(d)<smiles>NC(=S)Nc1c(Cl)ccc2nsnc12</smiles>

(b)<smiles>Nc1c(Cl)ccc2nsnc12</smiles><smiles>N=C(NCCNC(=N)Nc1c(Cl)ccc2nsnc12)Nc1c(Cl)ccc2nsnc12</smiles>

(c)<smiles>N=C(Nc1c(Cl)ccc2nsnc12)N(C1=NCCN1)c1c(Cl)ccc2nsnc12</smiles>

Figure 2. Structure of Tizanidine Impurities. (a) Impurity A (b) Impurity B (c) Impurity C (d) Impurity D (e) Impurity E (f) Impurity F. 
Merck. Triethylamine used was also AR grade and procured from Merck. Purified water for UPLC was obtained through Milli Q Water generating system. $0.45 \mu$ Millipore Durapore hydrophilic membrane filters were used for sample solution filtration.

\section{Equipment}

Waters Acquity UPLC with solvent manager to handle two mobile phases, auto injector and photo diode array detector. Waters Empower 2 chromatographic data system. Sonicator, $\mathrm{pH}$ meter (Mettler) and Micro balance (Mettler), Water bath and vacuum filtration pump. Syringe filters were used for the sample filtration.

\section{Method}

\section{Chromatography conditions}

The chromatography system used was Waters Acquity UPLC. The analytical column was ethylene bridged hybrid (BEH) C8 with dimensions of $100 \times 2.1,1.7 \mu \mathrm{m}$. Binary gradient mode elution mode was set to operate the chromatograph to achieve separation of all the related impurities of Tizanidine hydrochloride. Mobile phase A was made by mixing acetonitrile and buffer in the ratio of 5:95 $(v / v)$. Buffer for mobile phase A was made with $0.24 \%$ sodium perchlorate solution containing $0.6 \mathrm{ml} / 1$ triethyl amine and $\mathrm{pH}$ adjusted with orthophosphoric acid to 3.6. Mobile phase B was a mixture of acetonitrile and buffer in the ratio of $70: 30(v / v)$. Buffer for Mobile phase B was made with $0.67 \%$ sodium perchlorate containing $1.7 \mathrm{ml} / \mathrm{l}$ of triethylamine and $\mathrm{pH}$ adjusted to 2.6 using orthophosphoric acid.

Gradient program (T/\%B) used was as Initial $/ 0,1.00 / 0$, $5.00 / 20,11.00 / 50,13.00 / 20,16.00 / 0$, and 20.00/0. The flow rate was $0.5 \mathrm{ml} / \mathrm{minute}$ with $2 \mu \mathrm{l}$ injection volume, oven temperature for column was $60^{\circ} \mathrm{C}$ and UV detector set at $230 \mathrm{~nm}$. UPLC operation, data collation, and integration of chromatogram was performed using Waters Empower 2 software.

\section{Diluent preparation}

Diluent was prepared by mixing Mobile phase B and Acetonitrile in 80:20 (v/v) ratio.

\section{Preparation of resolution solution}

Considering that Tizanidine related impurity A and Tizanidine hydrochloride elute very closely, resolution solution in the diluent was prepared using a mixture of Tizanidine related Impurity A of concentration $0.001 \mathrm{mg} / \mathrm{ml}$ and Tizanidine hydrochloride of concentration $0.2 \mathrm{mg} / \mathrm{ml}$ to demonstrate method suitability.

\section{Standard preparation}

Tizanidine hydrochloride stock standard solution of concentration of $0.69 \mathrm{mg} / \mathrm{ml}$ was prepared by dissolving in diluent with little sonication. Tizanidine standard stock solution was further diluted to obtain concentration of $1.725 \mu \mathrm{g} / \mathrm{ml}$. Diluted standard solution was filtered through $0.45 \mu \mathrm{m}$ Durapore hydrophilic membrane filter prior to injecting in the chromatographic system.

\section{Test preparation}

Sample solution was prepared by crushing not less than 20 tablets of Tizanidine hydrochloride into fine powder. Tizanidine sample solution of concentration $0.5 \mathrm{mg} / \mathrm{ml}$ was prepared with tablet powder equivalent to $25 \mathrm{mg}$ of Tizanidine in $50 \mathrm{ml}$ of diluent with sonication for 15 minutes with intermittent shaking. About $2 \mathrm{ml}$ of test preparation solution was filtered through 0.45 $\mu \mathrm{m}$ Durapore hydrophilic membrane filter prior to injecting into the chromatographic system.

\section{RESULTS AND DISCUSSION}

\section{Forced degradation study}

Forced degradation study was performed in accordance with the ICH guidance by exposing the Tizanidine hydrochloride tablets as well as the placebo. Degradation study didn't yield significant degradation. This was due to precipitation after adding reagents. Thus, the reagent volume and stress time was reduced to avoid precipitation. There were no interfering peaks at the retention time of Tizanidine, tizanidine placebo, or at the retention time of the tizanidine related impurities. Chromatographic review did not throw up any purity flags. About $0.06 \%$ degradation was achieved under thermal conditions and $0.03 \%$ under alkali conditions. Result showed lower purity angle as against the purity threshold and there is no placebo interference. Details of the degradation levels are summarized in Table 2.

\section{Sample preparation optimization}

Sample preparation technique is critical and has significant impact on precision and accuracy of the method. Diluents such as acetonitrile, methanol, and various combination with buffer were tried to obtain good extraction of the active drug and ensure accurate response. Acetonitrile as well as methanol produced complete solubilization of the analyte and all impurities. However, the acetonitrile was selected as it gave strong analyte response, good peak shapes, and higher recovery.

\section{Chromatographic condition optimization}

Commonly used columns like C8 and C18 were evaluated. $\mathrm{C} 8$ sorbent was selected as it is less retentive compared to $\mathrm{C} 18$ sorbent. $\mathrm{C} 18$ was found not suitable, due to low resolution and asymmetric peak shape. Bonded BEH column was chosen considering low $\mathrm{pH}$ of the mobile phase and to avoid column bleeding. Separation between the most closely eluting impurity Tizanidine related impurity A and Tizanidine was achieved on the Waters Acquity BEH C8 column of dimensions $100 \times 2.1$, $1.7 \mu \mathrm{m}$. Varied composition of mobile phase using acetonitrile and methanol were studied. Good response and separation were seen with the mixture of mobile phase A composed of Sodium perchlorate, Triethylamine buffer $(\mathrm{pH} 3.6)$ and acetonitrile in ratio 95:5 $(v / v)$ and mobile phase B Sodium perchlorate, Triethylamine buffer $(\mathrm{pH} 2.6)$, and acetonitrile in the ratio 30:70 $(v / v)$ in gradient elution mode. Peaks were well separated at flow of $0.5 \mathrm{ml} /$ minute with column temperature $50^{\circ} \mathrm{C}$ and injection volume of $2 \mu \mathrm{l}$. To overcome the appearance of an impurity close to the Tizanidine peak, the column oven temperature was increased to $60^{\circ} \mathrm{C}$. This change ensured resolution of all the impurity peaks. The wavelength for measurement was selected as UV $230 \mathrm{~nm}$ based on the absorption maxima. Results were statistically assessed as a part of the method validation using mean, relative standard deviations, standard deviation, correlation coefficient considering 95\% confidence interval at appropriate places. 
Table 2. Degradation study - results of interference from degradation products.

\begin{tabular}{|c|c|c|c|c|c|c|}
\hline S.No & Degradation type & Conditions & $\begin{array}{c}\% \\
\text { Degradation }\end{array}$ & $\begin{array}{c}\text { Purity } \\
\text { angle }\end{array}$ & $\begin{array}{c}\text { Purity } \\
\text { threshold }\end{array}$ & $\begin{array}{c}\text { Purity } \\
\text { flag }\end{array}$ \\
\hline 1 & Test as such & Room temperature & Nil & 0.038 & 0.387 & No \\
\hline 2 & Acid degradation ${ }^{\mathrm{a}}$ & $\begin{array}{l}5 \mathrm{ml} \text { of } 1 \mathrm{~N} \mathrm{HCl} \text { solution for } 6 \text { hours at } 60^{\circ} \mathrm{C} \text { temperature on } \\
\text { water bath. }\end{array}$ & Nil & 0.034 & 0.386 & No \\
\hline 3 & Base degradation ${ }^{a}$ & $5 \mathrm{ml} 0.5 \mathrm{~N} \mathrm{NaOH}$ solution for 5 minutes at $70^{\circ} \mathrm{C}$ on water bath. & 0.03 & 0.026 & 0.460 & No \\
\hline 4 & Peroxide egradation ${ }^{\mathrm{a}}$ & $\begin{array}{l}5 \mathrm{ml} \text { of } 1 \% \text { Hydrogen peroxide }\left(\mathrm{H}_{2} \mathrm{O}_{2}\right) \text { for } 3 \text { hours at room } \\
\text { temperature }\end{array}$ & Nil & 0.022 & 0.445 & No \\
\hline 5 & Water degradation $^{\mathrm{a}}$ & $5 \mathrm{ml}$ of water for 12 hours at $60^{\circ} \mathrm{C}$ & Nil & 0.038 & 0.384 & No \\
\hline 6 & Thermal degradation & $120^{\circ} \mathrm{C} / 24$ hours & 0.06 & 0.034 & 0.372 & No \\
\hline 7 & $\begin{array}{l}\text { UV and visible light degradation } \\
\text { (Photolytic degradation) }\end{array}$ & $\begin{array}{l}200 \text {-watt hours } / \mathrm{m}^{2} \\
1.2 \text { million lux hours }\end{array}$ & Nil & 0.039 & 0.375 & No \\
\hline 8 & Humidity degradation & $90 \% \mathrm{RH}$ at $25^{\circ} \mathrm{C}$ for 7 days & 0.001 & 0.036 & 0.364 & No \\
\hline
\end{tabular}

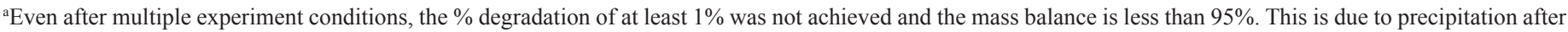
adding the reagents. Hence reagent volume and stress time were reduced to avoid precipitation.

Table 3. Comparison of RP-HPLC and developed UPLC method.

\begin{tabular}{|c|c|c|c|c|c|c|}
\hline \multirow[b]{2}{*}{ No. } & \multirow[b]{2}{*}{ Tizanidine impurity } & \multicolumn{2}{|c|}{ RP- HPLC method } & \multicolumn{2}{|c|}{ UPLC method } & \multirow[t]{2}{*}{ Advantages/disadvantages } \\
\hline & & $\begin{array}{l}\text { Relative retention } \\
\text { time (RRT) }\end{array}$ & $\begin{array}{l}\text { Retention time } \\
\text { (minutes) }\end{array}$ & $\begin{array}{l}\text { Relative retention } \\
\text { time (RRT) }\end{array}$ & $\begin{array}{l}\text { Retention time } \\
\text { (minutes) }\end{array}$ & \\
\hline \multirow{7}{*}{1} & Impurity A & 0.88 & 8.872 & 0.85 & 1.991 & \multirow{7}{*}{$\begin{array}{l}\text { All six known impurities } \\
\text { elute with HPLC as well as } \\
\text { UPLC method }\end{array}$} \\
\hline & Tizanidine (main peak) & 1.00 & 10.014 & 1.00 & 2.331 & \\
\hline & Impurity B & 1.51 & 14.405 & 1.37 & 3.220 & \\
\hline & Impurity $\mathrm{C}$ & 1.65 & 16.105 & 2.03 & 4.793 & \\
\hline & Impurity D & 2.24 & 29.885 & 2.2 & 5.186 & \\
\hline & Impurity E & 3.11 & 29.264 & 3.12 & 7.368 & \\
\hline & Impurity F & 3.15 & 30.386 & 4.48 & 10.449 & \\
\hline 2 & Resolution & $\begin{array}{l}\text { (a) Impurity B and C } \\
\text { elute very closely at } \\
1.551 \text { and } 1.65 \text { RRT } \\
\text { (b) Impurity E and F } \\
\text { elute very closely at } \\
3.11 \text { and } 3.15 \text { RRT }\end{array}$ & - & $\begin{array}{c}\text { (a) Impurity B and C } \\
\text { elute at } 1.37 \text { and } 2.03 \\
\text { RRT } \\
\text { (b) Impurity E and F } \\
\text { elute at } 3.12 \text { and } 4.48 \\
\text { RRT }\end{array}$ & - & $\begin{array}{l}\text { UPLC resolution of closely } \\
\text { eluting impurities is } \\
\text { significantly improved in } \\
\text { comparison to HPLC method }\end{array}$ \\
\hline 3 & Total run time & - & About 32 minutes & - & About 11 minutes & $\begin{array}{l}34 \% \text { reduction in run time } \\
\text { by UPLC }\end{array}$ \\
\hline
\end{tabular}

\section{Literature method assessment}

RP-HPLC method for Tizanidine hydrochloride referred in the literature was compared with the current developed UPLC method (Reddy et al., 2008). Advantage with the UPLC method was that the resolution between Impurity B and C, as well as between Impurity $\mathrm{E}$ and $\mathrm{F}$ improved significantly. Also, the run time was significantly reduced from about 32 minutes by RPHPLC method to less than 11 minutes by the developed UPLC method. A detailed comparison of the RP-HPLC and developed UPLC method for Tizanidine hydrochloride is shown in Table 3.

\section{Method Validation}

The developed UPLC method was validated on the lines of ICH Q2R1 guideline. Parameters such as system suitability test, specificity, limit of detection (LOD), limit of quantitation (LOQ), linearity and range, precision, accuracy, solution stability, and robustness were run in order to demonstrate the capability of the method.

\section{System suitability}

System suitability test was conducted by injecting resolution solution and six replicate injections of diluted tizanidine standard solution. The resolution of 5.6 was obtained between Tizanidine related Impurity A and Tizanidine. Peak area of six replicates of the tizanidine standard solution injection had an RSD (Relative standard deviation) of $0.9 \%$. The relative retention time of Tizanidine impurity A, Tizanidine impurity B, Tizanidine impurity C, Tizanidine impurity D, Tizanidine impurity E, and Tizanidine impurity $\mathrm{F}$ were about $0.85,1.37,2.03,2.30,3.12$, and 4.48, respectively. Tizanidine standard chromatogram and resolution solution showing separation of Tizanidine related impurity A and Tizanidine are shown in Figures 3 and 4, respectively. 


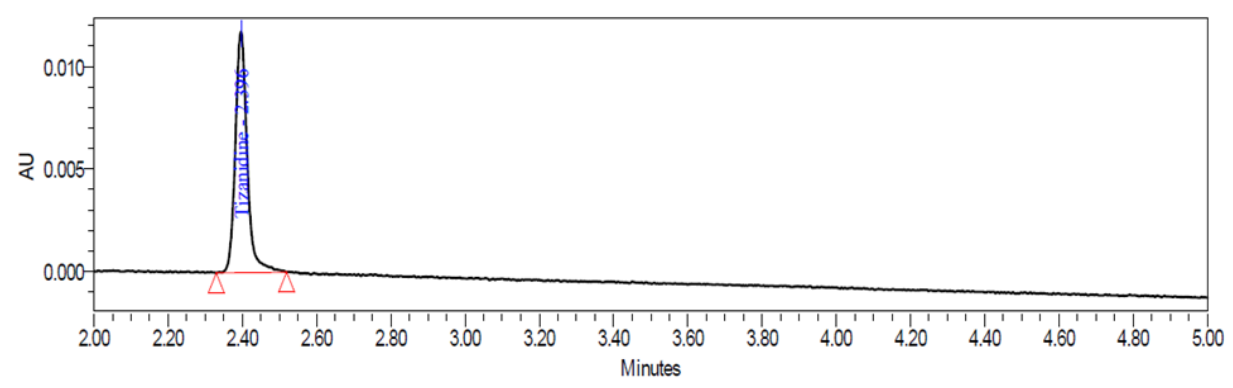

Figure 3. Tizanidine standard chromatogram.

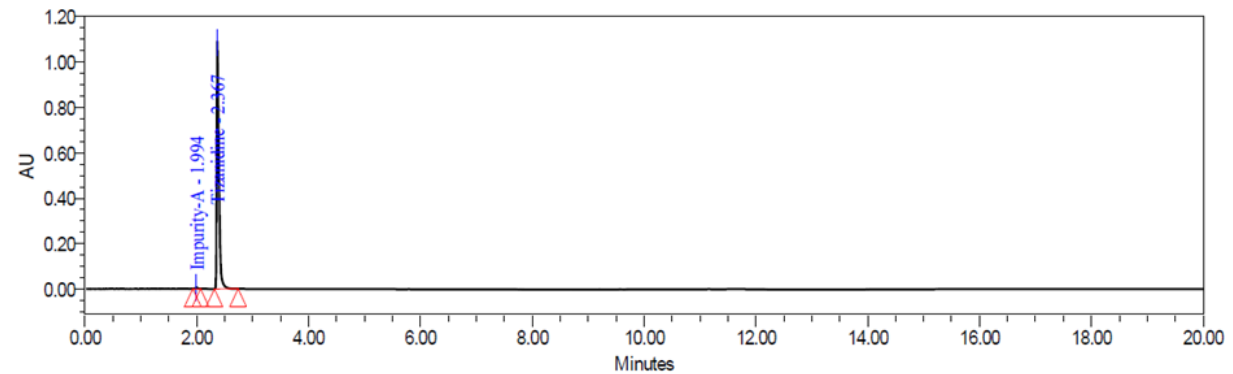

Figure 4. Resolution chromatogram: Separation of Tizanidine impurity A and Tizanidine.

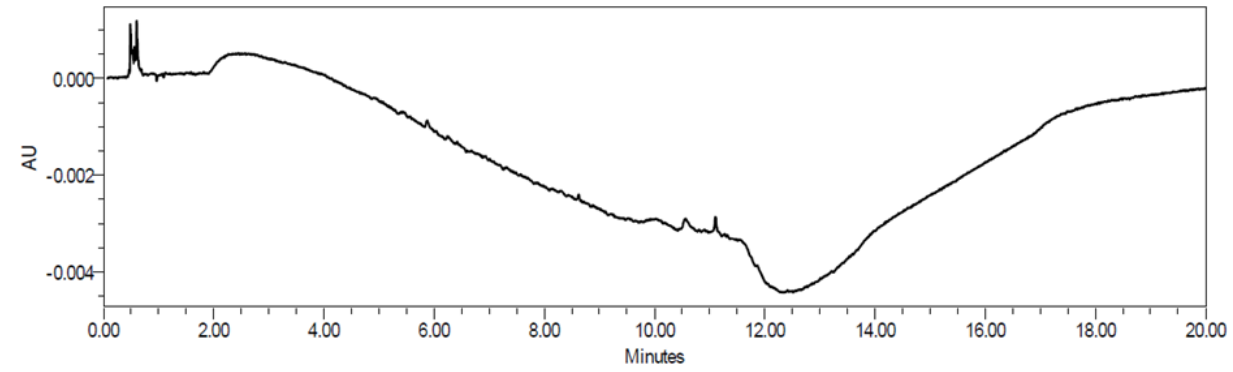

Figure 5. Placebo chromatogram.

\section{Specificity}

The study was conducted with placebo to establish the interference of placebo. The chromatograms of placebo showed no peaks at the retention time of Tizanidine and the known impurities. Placebo chromatogram is shown in Figure 5. Degradation study indicate that there are no interfering peaks at retention time of Tizanidine, tizanidine placebo, or at the retention time of the tizanidine related impurities. The purity angle was less than the purity thresholds.

\section{Limit of detection (LOD) and limit of quantitation (LOQ)}

The LOD and LOQ concentrations were established using signal-to-noise ratio method by spiking all known impurities and Tizanidine hydrochloride in the placebo. LOD was established as $0.017 \%, 0.008 \%, 0.013 \%, 0.020 \%, 0.018 \%, 0.028 \%$, and $0.015 \%$ for Tizanidine Impurity A, B, C, D, E, F, and Tizanidine, respectively. Similarly, the LOQ was established as $0.057 \%$, $0.037 \%, 0.037 \%, 0.051 \%, 0.051 \%, 0.048 \%$, and $0.055 \%$ for Tizanidine Impurity A, B, C, D, E, F, and Tizanidine, respectively. The details of LOD and LOQ for each impurity are summarized along with signal to noise ratio in Table 4.
Table 4. Tizanidine related impurities LOD and LOQ levels with $\mathrm{S} / \mathrm{N}$ ratio.

\begin{tabular}{ccccc}
\hline $\begin{array}{c}\text { Tizanidine } \\
\text { related impurity }\end{array}$ & $\begin{array}{c}\text { LOD } \\
\mathbf{( \% )}\end{array}$ & $\begin{array}{c}\text { S/N ratio } \\
\text { for LOD }\end{array}$ & LOQ (\%) & $\begin{array}{c}\text { S/N ratio } \\
\text { for LOQ }\end{array}$ \\
\hline Impurity-A & 0.017 & 4.4 & 0.057 & 12.8 \\
Impurity-B & 0.008 & 3.0 & 0.037 & 13.1 \\
Impurity-C & 0.013 & 4.4 & 0.037 & 12.7 \\
Impurity-D & 0.020 & 5.4 & 0.051 & 15.6 \\
Impurity-E & 0.018 & 3.5 & 0.051 & 10.4 \\
Impurity-F & 0.028 & 4.9 & 0.048 & 11.6 \\
Tizanidine & 0.015 & 4.1 & 0.055 & 15.4 \\
\hline
\end{tabular}

Precision was performed with six preparations of Tizanidine hydrochloride and all known related impurities of Tizanidine at limit of quantification level. The \% RSD observed to be $4.7 \%, 5.9 \%, 3.9 \%, 1.6 \%, 1.8 \%, 1.7 \%$, and $2.5 \%$ for Impurity A, B, C, D, E, F, and Tizanidine, respectively. Details are tabulated in Table 5. Typical chromatogram depicting all the impurities at LOQ level is shown in Figure 6. 
Table 5. Precision of Tizanidine related impurities at LOQ level.

\begin{tabular}{cccccccc}
\hline Sample no. & \multicolumn{9}{c}{ Tizanidine related impurities (\%) } \\
\hline- & Impurity A & Impurity B & Impurity C & Impurity D & Impurity E & Impurity F & Tizanidine \\
\hline 1 & 0.048 & 0.027 & 0.040 & 0.046 & 0.045 & 0.037 & 0.047 \\
2 & 0.048 & 0.028 & 0.038 & 0.045 & 0.046 & 0.038 & 0.045 \\
3 & 0.052 & 0.030 & 0.038 & 0.047 & 0.044 & 0.038 & 0.048 \\
4 & 0.050 & 0.030 & 0.039 & 0.046 & 0.045 & 0.038 & 0.047 \\
5 & 0.050 & 0.030 & 0.042 & 0.046 & 0.044 & 0.039 & 0.048 \\
6 & 0.054 & 0.032 & 0.039 & 0.045 & 0.044 & 0.038 & 0.048 \\
Average & 0.050 & 0.030 & 0.039 & 0.046 & 0.045 & 0.038 & 0.047 \\
\%RSD & 4.7 & 5.9 & 3.9 & 1.6 & 1.8 & 1.7 & 2.5 \\
$95 \%$ confidence interval & $0.048 \& 0.052$ & $0.029 \& 0.031$ & $0.038 \& 0.040$ & $0.045 \& 0.047$ & $0.044 \& 0.046$ & $0.038 \& 0.039$ & $0.046 \& 0.048$ \\
\hline
\end{tabular}

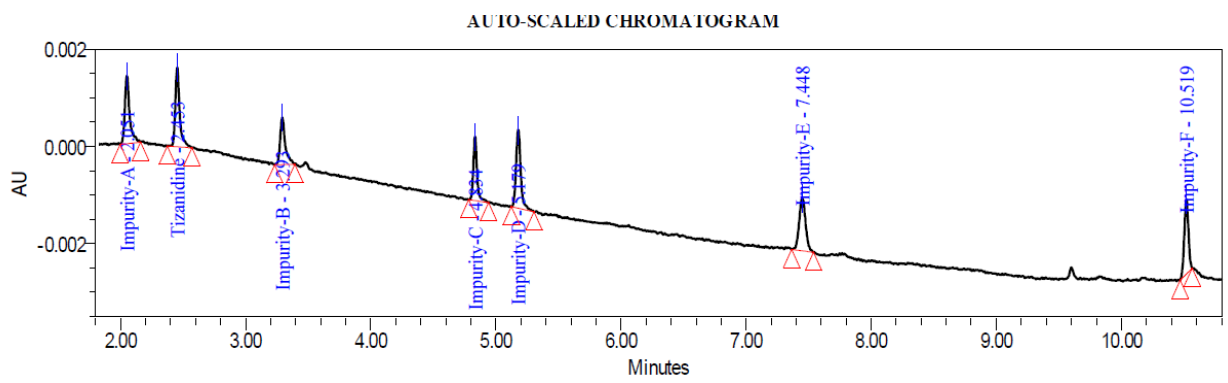

Figure 6. Typical chromatogram depicting all the impurities at LOQ level.

Accuracy was performed with three test preparations, with all known related impurities, and Tizanidine at limit of quantification level. The $\%$ mean recovery was observed to be $105.8 \%, 97.6 \%, 108.1 \%, 96.7 \%, 97.7 \%, 91.7 \%$, and $96.8 \%$ for Impurity A, B, C, D, E, F, and Tizanidine, respectively. Details are tabulated in Table 6 .

\section{Linearity and range}

Linearity and range were established by drawing a graph of concentration against the peak area response for the six known related impurities and Tizanidine hydrochloride and determining the correlation coefficient. The linearity of method for each impurity was assessed by drawing a six-point calibration graph in the range between LOQ and $150 \%$ levels. Linearity plot results are shown in Table 7 and linearity graphs are shown in Figure 7. The correlation coefficient value was more than 0.997 and Bias for $100 \%$ was not more than $\pm 5 \%$ for all known impurities and Tizanidine hydrochloride. This shows the method is sensitive in the given range, and the method can quantify all the known tizanidine related impurities.

\section{Precision}

Method precision was checked by injecting six samples prepared by spiking test preparation with all known related impurities at $0.2 \%$ levels. The $\%$ RSD was found to be $0.8 \%, 1.6 \%$, $1.5 \%, 0.4 \%, 1.9 \%, 2.1 \%$, and $1.2 \%$ for the related impurity A, B, C, D, E, F, and Tizanidine at 95\% confidence interval, respectively. The individual impurity level, RSD, and 95\% confidence intervals are detailed in Table 8 as a part of method precision. Typical chromatogram depicting all impurities is shown in Figure 8.
Intermediate precision was checked by injecting six samples prepared by spiking test preparation with all known related impurities at $0.2 \%$ level on different day. The $\%$ RSD was found to be $0.9 \%, 1.0 \%, 0.8 \%, 2.3 \%, 1.2 \%, 1.1 \%$, and $0.4 \%$ for the related impurity A, B, C, D, E, F, and Tizanidine at $95 \%$ confidence interval, respectively. The individual impurity level, RSD and 95\% confidence intervals are detailed in Table 9 as a part of intermediate precision.

\section{Accuracy}

The accuracy of test method for all known related impurities and tizanidine was performed by spiking impurities in the test preparation. Three samples each for 50\% and 100\% levels and six samples at $150 \%$ levels were prepared by spiking and injected into the chromatographic system. The percentage recovery of tizanidine impurity A, B, C, D, E, F, and Tizanidine across the $50 \%, 100 \%$, and $150 \%$ levels were in the range $88.2 \%-110.3 \%$ at $95 \%$ confidence intervals. The accuracy data is tabulated and presented in Table 10 .

\section{Solution stability}

Solution stability for the Mobile phase, Tizanidine standard, Tizanidine test solution was established for a period of 5 days at bench top conditions. The mobile phase was assessed for the $\%$ impurity from initial to 5 days and it was observed to be below $0.02 \%$ and total impurities below $1.5 \%$. The Tizanidine standard and test solution was assessed by evaluating the similarity factor of the standard solution which was observed to be between 1.0 and 1.03 from initial to 5 days. \% total impurity was found maximum to an extent of $2.2 \%$. 
Table 6. Accuracy of Tizanidine related impurities at LOQ level.

\begin{tabular}{|c|c|c|c|c|c|}
\hline Name of the impurity & Sample No. & “ $\mu \mathrm{g} / \mathrm{ml}$ ” Impurity added & " $\mu \mathrm{g} / \mathrm{ml}$ " impurity found & \% Recovery & Mean\% recovery \\
\hline & 1 & & 0.261285 & 104.6 & \\
\hline \multirow[t]{3}{*}{ Impurity-A } & 2 & 0.249774 & 0.262235 & 105.0 & 105.8 \\
\hline & 3 & & 0.269400 & 107.9 & \\
\hline & 1 & & 0.186260 & 100.2 & \\
\hline \multirow[t]{3}{*}{ Impurity-B } & 2 & 0.185903 & 0.170425 & 91.7 & 97.6 \\
\hline & 3 & & 0.187620 & 100.9 & \\
\hline & 1 & & 0.213025 & 109.8 & \\
\hline \multirow[t]{3}{*}{ Impurity-C } & 2 & 0.193949 & 0.212410 & 109.5 & 108.1 \\
\hline & 3 & & 0.203550 & 105.0 & \\
\hline & 1 & & 0.232885 & 98.5 & \\
\hline \multirow[t]{3}{*}{ Impurity-D } & 2 & 0.236415 & 0.227215 & 96.1 & 96.7 \\
\hline & 3 & & 0.226080 & 95.6 & \\
\hline & 1 & & 0.247745 & 98.4 & \\
\hline \multirow[t]{3}{*}{ Impurity-E } & 2 & 0.251827 & 0.247415 & 98.2 & 97.7 \\
\hline & 3 & & 0.243200 & 96.6 & \\
\hline & 1 & & 0.225265 & 91.7 & \\
\hline \multirow[t]{3}{*}{ Impurity-F } & 2 & 0.245559 & 0.225665 & 91.9 & 91.7 \\
\hline & 3 & & 0.224630 & 91.5 & \\
\hline & 1 & & 0.235565 & 97.3 & \\
\hline \multirow[t]{2}{*}{ Tizanidine } & 2 & 0.242133 & 0.226480 & 93.5 & 96.8 \\
\hline & 3 & & 0.240890 & 99.5 & \\
\hline
\end{tabular}

Table 7. Linearity plot details of Tizanidine and its impurities.

\begin{tabular}{|c|c|c|c|c|c|c|c|c|}
\hline \multirow{2}{*}{ S. No } & \multicolumn{2}{|c|}{ Impurity A } & \multicolumn{2}{|c|}{ Impurity B } & \multicolumn{2}{|c|}{ Impurity $\mathrm{C}$} & \multicolumn{2}{|c|}{ Impurity D } \\
\hline & $\mu \mathrm{g} / \mathrm{ml}$ & Area & $\mu \mathrm{g} / \mathrm{ml}$ & Area & $\mu \mathrm{g} / \mathrm{ml}$ & Area & $\mu \mathrm{g} / \mathrm{ml}$ & Area \\
\hline 1 & 0.2498 & 4,074 & 0.1866 & 2,401 & 0.2061 & 2,778 & 0.2364 & 4,430 \\
\hline 2 & 0.4995 & 7,983 & 0.4975 & 8,954 & 0.4849 & 6,613 & 0.4728 & 8,874 \\
\hline 3 & 0.7493 & 11,915 & 0.7462 & 14,897 & 0.7273 & 10,181 & 0.7092 & 13,459 \\
\hline 4 & 0.9991 & 16,335 & 0.9950 & 18,319 & 0.9697 & 14,044 & 0.9457 & 18,005 \\
\hline 5 & 1.2489 & 20,346 & 1.2437 & 23,070 & 1.2122 & 17,126 & 1.1821 & 22,543 \\
\hline 6 & 1.5986 & 24,461 & 1.5919 & 29,948 & 1.5516 & 20,844 & 1.5131 & 27,299 \\
\hline Correlation coefficient & \multicolumn{2}{|c|}{0.998074} & \multicolumn{2}{|c|}{0.998179} & \multicolumn{2}{|c|}{0.998013} & \multicolumn{2}{|c|}{0.998534} \\
\hline Intercept & \multicolumn{2}{|c|}{410.175048} & \multicolumn{2}{|c|}{-663.048063} & \multicolumn{2}{|c|}{171.928155} & \multicolumn{2}{|c|}{407.505075} \\
\hline Slope & \multicolumn{2}{|c|}{$15,463.022844$} & \multicolumn{2}{|c|}{$19,306.067094$} & \multicolumn{2}{|c|}{$13,695.102889$} & \multicolumn{2}{|c|}{$18,216.940989$} \\
\hline Bias at $100 \%$ & \multicolumn{2}{|c|}{2.51} & \multicolumn{2}{|c|}{-3.62} & \multicolumn{2}{|c|}{1.22} & \multicolumn{2}{|c|}{2.26} \\
\hline Residual sum of square & \multicolumn{2}{|c|}{$1,131,449.058050$} & \multicolumn{2}{|c|}{$1,765,425.234706$} & \multicolumn{2}{|c|}{$897,220.235563$} & \multicolumn{2}{|c|}{$1,070,078.157873$} \\
\hline
\end{tabular}

Table 7 (continued). Linearity plot details of Tizanidine and its impurities.

\begin{tabular}{|c|c|c|c|c|c|c|}
\hline \multirow{2}{*}{ S. No } & \multicolumn{2}{|c|}{ Impurity E } & \multicolumn{2}{|c|}{ Impurity F } & \multicolumn{2}{|c|}{ Tizanidine } \\
\hline & $\mu \mathrm{g} / \mathrm{ml}$ & Area & $\mu \mathrm{g} / \mathrm{ml}$ & Area & $\mathrm{g} / \mathbf{m l}$ & Area \\
\hline 1 & 0.2518 & 4,005 & 0.2456 & 3,786 & 0.2421 & 4,283 \\
\hline 2 & 0.5037 & 8,337 & 0.4911 & 7,603 & 0.7264 & 12,482 \\
\hline 3 & 0.7555 & 12,547 & 0.7367 & 11,648 & 1.0896 & 18,572 \\
\hline 4 & 1.0073 & 17,038 & 0.9822 & 15,672 & 1.5739 & 27,112 \\
\hline 5 & 1.2591 & 21,628 & 1.2278 & 19,447 & 1.9371 & 33,024 \\
\hline
\end{tabular}




\begin{tabular}{|c|c|c|c|c|c|c|}
\hline \multirow{2}{*}{ S. No } & \multicolumn{2}{|c|}{ Impurity E } & \multicolumn{2}{|c|}{ Impurity F } & \multicolumn{2}{|c|}{ Tizanidine } \\
\hline & $\mu \mathrm{g} / \mathrm{ml}$ & Area & $\mu \mathrm{g} / \mathrm{ml}$ & Area & $\mathrm{g} / \mathrm{ml}$ & Area \\
\hline 6 & 1.6117 & 26,528 & 1.5716 & 23,604 & 2.3003 & 40,283 \\
\hline Correlation coefficient & \multicolumn{2}{|c|}{0.999157} & \multicolumn{2}{|c|}{0.998395} & \multicolumn{2}{|c|}{0.999692} \\
\hline Intercept & \multicolumn{2}{|c|}{-81.685336} & \multicolumn{2}{|c|}{308.007469} & \multicolumn{2}{|c|}{-133.211595} \\
\hline Slope & \multicolumn{2}{|c|}{$16,806.723204$} & \multicolumn{2}{|c|}{$15,206.842090$} & \multicolumn{2}{|c|}{$17,352.691383$} \\
\hline Bias at $100 \%$ & \multicolumn{2}{|c|}{-0.48} & \multicolumn{2}{|c|}{1.97} & \multicolumn{2}{|c|}{-0.49} \\
\hline Residual sum of square & \multicolumn{2}{|c|}{$593,113.472249$} & \multicolumn{2}{|c|}{$880,509.586559$} & \multicolumn{2}{|c|}{$550,060.308927$} \\
\hline
\end{tabular}
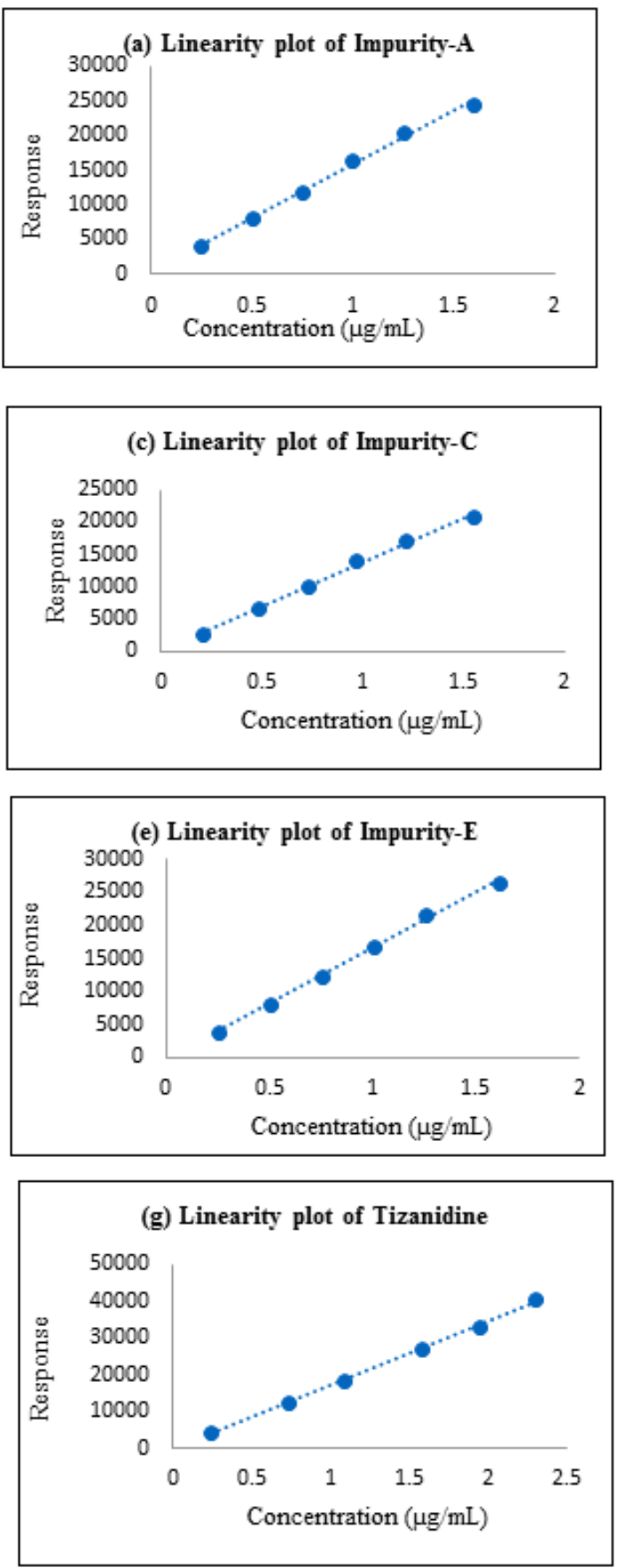
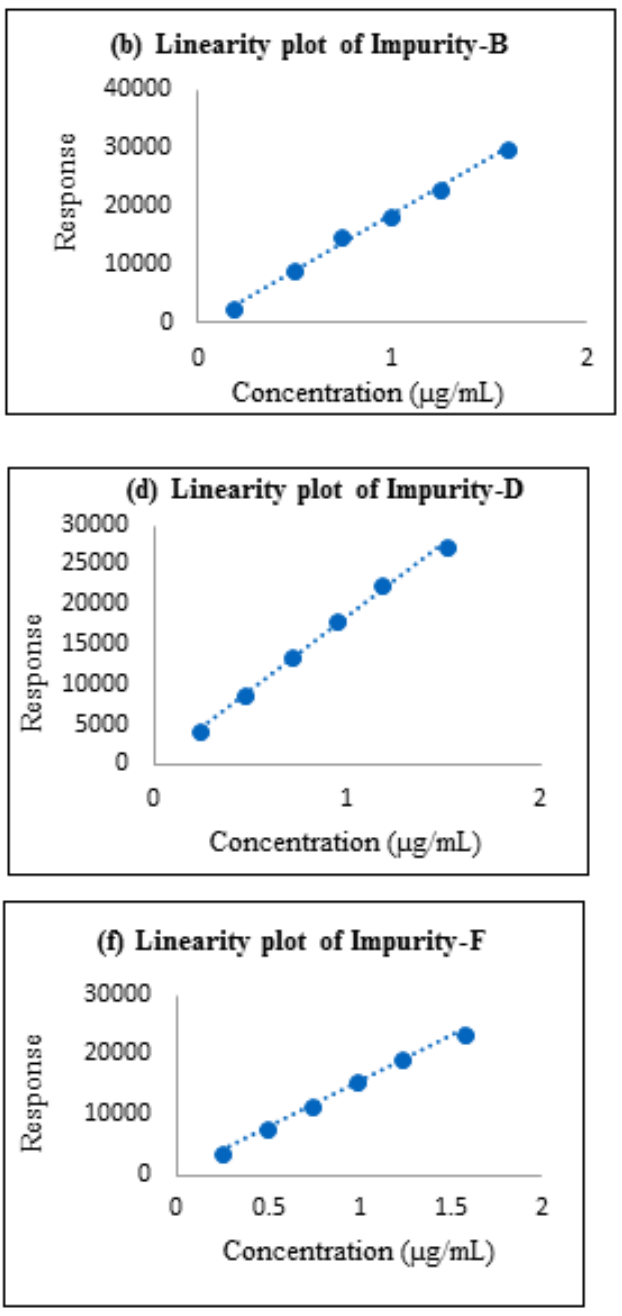

Figure 7. (a) Linearity plot of impurity A; (b) Linearity plot of impurity B; (c) Linearity plot of impurity C; (d) Linearity plot of impurity D; (e) Linearity plot of impurity E; (f) Linearity plot of impurity F; (g) Linearity plot of Tizanidine. 
Table 8. Method precision for the Tizanidine impurities and Tizanidine.

\begin{tabular}{cccccccc}
\hline \multirow{2}{*}{ Injection ID } & \multicolumn{7}{c}{ Impurities (\%) } \\
\cline { 2 - 8 } & Imp-A & Imp-B & Imp-C & Imp-D & Imp-E & Imp-F & Tizanidine \\
\hline 1 & 0.216 & 0.194 & 0.189 & 0.196 & 0.204 & 0.219 & 0.210 \\
2 & 0.216 & 0.193 & 0.188 & 0.194 & 0.202 & 0.216 & 0.208 \\
3 & 0.213 & 0.193 & 0.195 & 0.194 & 0.194 & 0.223 & 0.212 \\
4 & 0.217 & 0.196 & 0.187 & 0.196 & 0.204 & 0.223 & 0.207 \\
5 & 0.213 & 0.187 & 0.189 & 0.195 & 0.199 & 0.224 & 0.209 \\
6 & 0.215 & 0.193 & 0.190 & 0.196 & 0.204 & 0.229 & 0.205 \\
Average & 0.215 & 0.193 & 0.189 & 0.195 & 0.201 & 0.222 & 0.209 \\
\%RSD & 0.8 & 1.6 & 1.5 & 0.4 & 1.9 & 2.1 & 1.2 \\
\hline 95\% Confidence interval & $0.21 \& 0.21$ & $0.19 \& 0.19$ & $0.19 \& 0.19$ & $0.20 \& 0.20$ & $0.20 \& 0.20$ & $0.22 \& 0.22$ & $0.21 \& 0.21$ \\
\hline
\end{tabular}

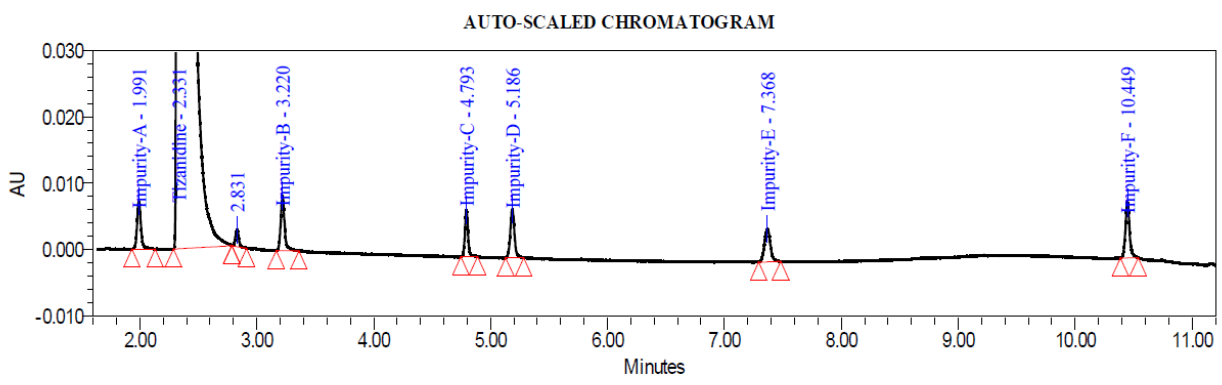

Figure 8. Precision - typical chromatogram depicting all the impurities.

Table 9. Intermediate Precision for the Tizanidine impurities and Tizanidine.

\begin{tabular}{cccccccc}
\hline \multirow{2}{*}{ Injection ID } & \multicolumn{9}{c}{ Impurities (\%) } \\
\cline { 2 - 8 } & Imp-A & Imp-B & Imp-C & Imp-D & Imp-E & Imp-F & Tizanidine \\
\hline 1 & 0.208 & 0.205 & 0.213 & 0.208 & 0.202 & 0.210 & 0.208 \\
2 & 0.209 & 0.205 & 0.209 & 0.209 & 0.203 & 0.209 & 0.208 \\
3 & 0.213 & 0.207 & 0.213 & 0.201 & 0.197 & 0.204 & 0.209 \\
4 & 0.211 & 0.206 & 0.214 & 0.209 & 0.200 & 0.206 & 0.209 \\
5 & 0.209 & 0.203 & 0.212 & 0.199 & 0.204 & 0.208 & 0.208 \\
6 & 0.211 & 0.209 & 0.212 & 0.201 & 0.201 & 0.205 & 0.207 \\
Average & 0.210 & 0.206 & 0.212 & 0.205 & 0.201 & 0.207 & 0.208 \\
\%RSD & 0.9 & 1.0 & 0.8 & 2.3 & 1.2 & 1.1 & 0.4 \\
\hline 95\% confidence interval & $0.209-0.211$ & $0.204-0.208$ & $0.211-0.213$ & $0.201-0.209$ & $0.199-0.203$ & $0.205-0.209$ & $0.207-0.209$ \\
\hline
\end{tabular}

Table 10. Accuracy data with spike level of $50 \%-150 \%$ of test preparation.

\begin{tabular}{cccc}
\hline $\begin{array}{c}\text { Tizanidine } \\
\text { related impurity }\end{array}$ & $\begin{array}{c}\text { Spike } \\
\text { level }\end{array}$ & \% recovery & $\begin{array}{c}\mathbf{9 5 \%} \text { confidence } \\
\text { interval }\end{array}$ \\
\hline Impurity A & $50 \%$ & $101.2 \%-107.1 \%$ & 101.3 and 108.5 \\
& $100 \%$ & $104.3 \%-106.1 \%$ & 104.0 and 106.2 \\
Impurity B & $150 \%$ & $103.3 \%-107 \%$ & 104.5 and 106.5 \\
& $50 \%$ & $88.2 \%-90.5 \%$ & 88.2 and 90.8 \\
& $100 \%$ & $92.8 \%-94.0 \%$ & 92.6 and 94.0 \\
Impurity C & $150 \%$ & $93.0 \%-95.8 \%$ & 94.1 and 95.9 \\
& $50 \%$ & $96.9 \%-105.9 \%$ & 96.4 and 106.6 \\
& $100 \%$ & $101.0 \%-106.2 \%$ & 100.7 and 106.7 \\
& $150 \%$ & $100.8 \%-103.1 \%$ & 100.9 and 102.5 \\
\hline
\end{tabular}

\begin{tabular}{cccc}
\hline Impurity D & $50 \%$ & $93.9 \%-94.7 \%$ & 93.9 and 94.9 \\
& $100 \%$ & $94.7 \%-99.2 \%$ & 93.3 and 99.1 \\
& $150 \%$ & $98.7 \%-100 \%$ & 99.0 and 99.8 \\
Impurity E & $50 \%$ & $92.8 \%-96.4 \%$ & 92.3 and 96.4 \\
& $100 \%$ & $96.1 \%-96.5 \%$ & 96.1 and 96.5 \\
& $150 \%$ & $96.0 \%-97.4 \%$ & 96.2 and 97.2 \\
Impurity F & $50 \%$ & $92.4 \%-95.2 \%$ & 92.4 and 95.8 \\
& $100 \%$ & $89.3 \%-94.1 \%$ & 89.0 and 94.4 \\
& $150 \%$ & $88.9 \%-91.4 \%$ & 89.3 and 90.3 \\
Tizanidine & $50 \%$ & $107.3 \%-110.3 \%$ & 107.3 and 110.9 \\
& $100 \%$ & $102.2 \%-104.3 \%$ & 102.1 and 104.3 \\
& $150 \%$ & $101.9 \%-102.9 \%$ & 101.7 and 102.5 \\
\hline
\end{tabular}


Table 11. Robustness - impact of system suitability for intentional changes in method parameters.

\begin{tabular}{lccc}
\hline Method parameters & Intentionally changed to & $\begin{array}{c}\text { Resolution between related } \\
\text { impurity A and Tizanidine }\end{array}$ & \% RSD \\
\hline Flow rate & $0.4 \mathrm{ml} /$ minute & 5.7 & 2.1 \\
& $0.5 \mathrm{ml} /$ minute & 5.6 & 0.9 \\
& $0.6 \mathrm{ml} /$ minute & 5.8 & 1.4 \\
Column oven temperature & $55^{\circ} \mathrm{C}$ & 5.6 & 2.0 \\
& $60^{\circ} \mathrm{C}$ & 5.6 & 0.9 \\
Mobile phase variation in organic & $65^{\circ} \mathrm{C}$ & 5.4 & 1.2 \\
phase (acetonitrile) & $90 \%$ & 4.2 & 1.6 \\
& $100 \%$ & 5.6 & 0.9 \\
Mobile phase variation in aqueous & $110 \%$ & 4.2 & 0.5 \\
phase & $90 \%$ & 4.1 & 0.5 \\
pH of mobile phase A & $100 \%$ & 5.6 & 0.7 \\
& $110 \%$ & 4.2 & 0.9 \\
pH of mobile phase B & 3.4 & 5.3 & 0.6 \\
& 3.6 & 5.6 & 0.9 \\
& 3.8 & 5.2 & 0.1 \\
& 2.4 & 4.7 & 0.9 \\
& 2.6 & 5.6 & 0.9 \\
& 2.8 & 4.3 & 0.9 \\
\hline
\end{tabular}

Similarly, stability for the resolution solution for system suitability was established for a period of 5 days under refrigerator conditions. The $\%$ assay difference of related impurity A was assessed at initial and up to 5 days period. It was observed to be below $3.5 \%$.

\section{Robustness}

Robustness of the UPLC method was verified by making intentional changes in flow rate, column oven temperature, composition of the organic phase and aqueous phase in mobile phase $\mathrm{A}$ and $\mathrm{B}, \mathrm{pH}$ of buffer for mobile phase $\mathrm{A}$ and $\mathrm{B}$. In each of the cases the UPLC method met the system suitability requirements of resolution and \%RSD criteria. Details of the intentional changes and the outcomes are listed in Table 11

\section{CONCLUSION}

In conclusion, a single, sensitive, precise, accurate, quick, and robust UPLC method was developed for quantitation of all known Tizanidine impurities in Tizanidine tablets. The specificity of the method was demonstrated by no interference from the degradation studies of the tablet formulation and placebo. The method is advantageous owing to it being one single method for all the known Tizanidine related impurities, LOD in range $0.008 \%-0.028 \%$, LOQ in the range $0.037 \%-0.057 \%$, lower runtime and simple sample preparation technique. Considering that quality control laboratories need efficient and cost-effective methods that are quick, low-cost considering solvent usage, and stability indicating, this UPLC method can be directly used for day to day and stability monitoring in the testing laboratories. In addition, the method can be used for testing of multiple samples due to the robust solution stability of mobile phase as well as the standard and sample solutions.

\section{AUTHOR CONTRIBUTIONS}

Each of the authors contributed as part of design, data collection, and interpretation. They also took part in drafting and revising portions of the article critically. All authors meet the qualification requirements in line with the international committee of medical journal editors.

\section{ACKNOWLEDGMENTS}

The author thanks Dr.Reddy's Laboratories for providing gift samples of Tizanidine hydrochloride, Tizanidine Hydrochloride tablets and Tizanidine related impurities.

\section{AUTHOR CONTRIBUTIONS}

All authors made substantial contributions to conception and design, acquisition of data, or analysis and interpretation of data; took part in drafting the article or revising it critically for important intellectual content; agreed to submit to the current journal; gave final approval of the version to be published; and agree to be accountable for all aspects of the work. All the authors are eligible to be an author as per the international committee of medical journal editors (ICMJE) requirements/guidelines.

\section{FUNDING}

There is no funding to report.

\section{CONFLICTS OF INTEREST}

The authors report no financial or any other conflicts of interest in this work.

\section{ETHICAL APPROVALS}

This study does not involve experiments on animals or human subjects. 


\section{PUBLISHER'S NOTE}

This journal remains neutral with regard to jurisdictional claims in published institutional affiliation.

\section{REFERENCES}

Brandalise M, Ferreira PCL, Meneghini L, Pereira AG, Froelich PE, Bergold AM. Stability-Indicating method for determination of Tizanidine Hydrochloride by LC-CAD method using chemometric approach. Drug Anal Res, 2017; 01:61-6.

Coward DM. Tizanidine: neuropharmacology and mechanism of action. Neurology, 1994; 44:S6-10.

Devarajan, Sivasubramanian L. Simultaneous spectrophotometric determination of valdecoxib and tizanidine in tablets. Indian J Pharm Sci, 2006; 68:240-2.

Mantri S, Moorthy NN, Kartthikeyan C, Trivedi P. Simultaneous spectrophotometric methods for the estimation of nimesulide and tizanidine in a tablet dosage form. Indian J Pharm Sci, 2005; 67:501-4.

Ramaa CS, Deshpande DK, Shirode AR, Wamorkar VV, Kakad AB, Kadam VJ. Reverse- phase high performance liquid chromatographic determination of tizanidine and valdecoxib in tablets. Indian J Pharm Sci, 2006; 68:514-6.

Reddy GM, Krishna SR, Rao MVNB, Satish BV, Himabindu $\mathrm{V}$. Identification and characterization of potential impurities of tizanidine hydrochloride ACAIJ, 2008; 7(8):586-90
Samel A, Raman B, Simultaneous estimation of related impurities of tizanidine hydrochloride in its active pharmaceutical ingradient by reversed-phase liquid chromatography. Asian J Chem, 2009, 21(1):176-82.

Smith C, Birnbaum G, Carter JL, Greenstein J, Lublin FD. Tizanidine treatment of spasticity caused by multiple sclerosis: results of a doubleblind, placebo-controlled trial. Neurology, 1994; 44:S34-43.

Subramanian G, Pandey S, Udupa N. RP-HPLC estimation of rofecoxib and tizanidine in combination tablets. Indian J Pharm Sci, 2004; 66:699-701.

Vijayakumar EKS, Gore VG, Mahajan A, Kumar M. Isolation and characterization of a process impurity in tizanidine hydrochloride Indian J Pharm Sci, 2010; 72(3):360-2.

Wagstaff AJ, Bryson HM, Tizanidine. A review of its pharmacology, clinical efficacy and tolerability in the management of spasticity associated with cerebral and spinal disorders. Drugs, 1997; $53: 435-52$.

\section{How to cite this article:}

Shetgar SS, Dharmasoth R, Keloth B, Rao BM. Development and validation of UPLC method for quantitative estimation of related impurities in tizanidine hydrochloride tablets. J Appl Pharm Sci, 2021; 11(08):043-053. 